\title{
Supportive Care Needs following Cancer Treatment: A Comparison of Breast and Brain Cancer in an Australian Cohort
}

\author{
Bhasker Amatya, ${ }^{1}$ Fary Khan, ${ }^{1,2,3}$ Louisa $\mathrm{Ng}^{1,2}$ and Mary Galea ${ }^{1,2}$ \\ ${ }^{1}$ Department of Rehabilitation Medicine, Royal Melbourne Hospital, 34-54 Poplar Road, Parkville, Melbourne, Victoria 3052, Australia \\ ${ }^{2}$ Department of Medicine (Royal Melbourne Hospital), The University of Melbourne, Parkville, Victoria 3052, Australia \\ ${ }^{3}$ School of Public Health and Preventive Medicine, Monash University, Clayton, Victoria 3800, Australia
}

Correspondence should be addressed to Bhasker Amatya; bhasker.amatya@mh.org.au

Received 15 November 2013; Accepted 16 December 2013; Published 20 January 2014

Academic Editors: H. Jia, K. Nas, and C. Zwingmann

Copyright (C) 2014 Bhasker Amatya et al. This is an open access article distributed under the Creative Commons Attribution License, which permits unrestricted use, distribution, and reproduction in any medium, provided the original work is properly cited.

\begin{abstract}
Objective. To assess and identify patient-reported supportive care needs following definitive treatment in persons with breast cancer (BC) and primary brain tumours (gliomas) (BT) in an Australian community cohort and to assess the commonalities and/or discrepancies of the reported needs in these oncological populations. Methods. A prospective cross-sectional survey of persons with BC $(n=85)$ and BT $(n=106)$ using questionnaires for supportive care needs, psychological morbidity, and quality of life. Results. BT participants were younger than BC patients (mean ages 51 and 57 years). The median time since diagnosis for both groups was over 2 years. The level of psychological morbidity, mainly depression, was high in both groups: BC (22\%) and BT (20\%). Participants in both groups reported at least one need ("met" or "unmet"). The BC patients reported higher numbers of "needs" and "unmet" needs compared with BT patients (mean 13.7 versus 11.6 needs; "unmet" needs mean 6.0 versus 4.1 ). The common "met" and "unmet" needs highlighted by both groups were comparable; the domain for most "met" needs included comprehensive cancer care, while "unmet" needs related to existential survivorship issues. Conclusion. Despite successful treatment many cancer survivors experience unmet supportive care needs in longer term. Understanding the impact of these beyond the acute phase is important as care shifts to community settings. More research in existential survivorship issues is needed.
\end{abstract}

\section{Introduction}

Cancer is a leading cause of death worldwide [1]. Breast cancer (BC) is the most common malignancy in women [1], comprising up to $16 \%$ of all cancers in women [2]. Primary brain tumours (BT), a comparatively rare and diverse group of neoplasms, account for $2 \%$ of all cancers [3] and affect 7 per 100,000 population annually worldwide [4]. The overall incidence of $\mathrm{BC}$ and $\mathrm{BT}$ is on increase worldwide [2]. In Australia, by 2015, 1 in 9 women will develop BC [5]. It is estimated that in 2009, there were 22,070 new cases of BT in United States $[6,7]$. In Australia, a similarly high incidence rate is reported, with approximately 1400 new cases and more than 1200 deaths annually [8]. The World Health Organisation (WHO) promotes the integration of prevention, early detection, diagnosis and treatment [9], rehabilitation and palliative care [2] in the management of. $\mathrm{BC}$ and $\mathrm{BT}$ within the national cancer control programs.
With recent therapeutic advances, survival rates of persons with cancers have improved [10-12]. However, recovery and treatment options after BC or BT can be challenging, and many survivors experience transient and/or persistent physical, functional, and psychosocial morbidities impacting everyday activities, participation (work, social activities), and quality of life (QoL) [12-14]. In the community, various issues may surface during transition: adjustment (self-worth, selfimage), coping with new demands associated with increased care needs, inability to return to driving and work, financial constraints, marital stress, and restriction in participation. Further, treatment regimens can be associated with complications and/or side-effects [14-16]. After treatment, many $\mathrm{BC}$ and $\mathrm{BT}$ patients report a range of psychological sequalae across the survivorship continuum (e.g., anxiety, depression, and sexual dysfunction) [17-19]. These disabilities can have a cumulative effect over time and cause considerable distress to the cancer survivors and their families and reduce QoL. 
There are significant costs and socioeconomic implications of increased demand for health care, social and vocational services, and caregiver burden [15].

A number of studies assessed QoL, psychosocial variables and patient satisfaction in cancer cohorts [20, 21]. These studies largely evaluated problems experienced by these patients but not whether help is required to manage these problems and if patients actually received the help required. This has resulted in the development of specific measures to more broadly assess cancer patients' needs and unmet needs by directly measuring the gap between a person's experience of a service and the actual service required [22]. Some studies have attempted to use this needs-based research approach in various oncological conditions, such as BC, gynaecological, prostate, and colorectal cancers, to evaluate the problems and "needs" cancer survivors experience [2326]. These studies were conducted in the acute care settings (hospital oncology clinics) and none address the extent of assistance/need experienced by the cancer survivors living in the community in Australian context. To our knowledge no studies compare the care needs amongst diverse cancer populations such as BC and BT. The primary objectives of this study therefore were to assess and identify supportive care needs in patients following definitive treatment for BC and BT in an Australian community cohort and to assess the commonalities and/or discrepancies of the reported needs in these oncological populations. The findings from this study will identify the needs from patients' perspective and will inform healthcare providers for potentially important factors impacting patients' everyday activities to facilitate optimal delivery of limited health care resources.

\section{Methods}

2.1. Participants and Setting. This cross-sectional study was part of a prospective rehabilitation outcomes oncological research program at the Royal Melbourne Hospital (RMH), a tertiary referral centre in Victoria, Australia and approved by its Human Research Ethics Committee (numbers 2010.203 and 2010.216). The recruitment process has been reported previously [27-29]. All consecutive patients with BC or BT (main diagnosis, first admission only) discharged to the community following acute treatment at RMH between 2007 and 2011 were identified. The RMH Access Database was used for cross-indexing of diseases from the Patient Administrator System of Hospital Information Systems, Department of Health, Victoria, Australia. Information in the database was from a pool of persons residing in the community, referred to the RMH from public and private medical clinics across greater Melbourne in Victoria. All participants were aged $>18$ years and fulfilled standard diagnostic criteria for BC as defined by the American Joint Committee on Cancer [30] and for BT using the grading system (grades I-IV) for gliomas as outlined by the WHO for Central Nervous System Tumours [31] and assessed by a surgeon/oncologist. Exclusion criteria included survival rate less than 4 months, benign and metastatic tumours, significant comorbidities or medically unstable, or psychiatric disorders (such as uncontrolled schizophrenia, actively suicidal/self-harm or physical aggressiveness (based on clinical judgment)) limiting participation in rehabilitation, and bed-bound and/or institutionalized in nursing homes.

2.2. Procedure. All 450 patients identified on the $\mathrm{RMH}$ Database ( $n=298 \mathrm{BC}$ and $152 \mathrm{BT}$ patients) were invited by mail to participate in the study and a total of 191 participants ( $n=85 \mathrm{BC}$ and $106 \mathrm{BT}$ patients) who consented were recruited. These participants undertook rehabilitation program, which provided acute surgical/oncological and rehabilitative care for inpatients and in ambulatory setting to minimize activity limitation and enhance participation.

2.2.1. Assessment. All assessments were completed in hospital clinics (or participants' homes) in a 6-week period, using a structured format, by three independent assessors. These assessors (two physicians, one research officer) were trained in cognitive and functional ability assessments (examined and accredited by a national body-the Australian Rehabilitation Outcomes Centre). They were not in contact with the acute surgical/oncological services or the rehabilitation treating teams and received separate clinical record forms. They completed demographic, functional assessments and healthrelated QoL measures using standardized instruments (see measures). These assessment interviews took approximately 30 minutes. The assessors did not prompt participants but provided assistance for those who had difficulty completing the questionnaires. All assessments were secured and filed and opened only at the time of entry into the database by an independent data entry officer.

\subsection{Measurement}

2.3.1. Demographic Characteristics. A self-reported questionnaire was used to gather basic demographic information and disease related data (surgery, pathology, treatments received, signs and symptoms, etc.).

2.3.2. Supportive Care Needs. Cancer survivor unmet needs measure (CaSUN) [22] assessed and identified needs experienced by cancer survivors within the preceding month. This included 35 need items: 6 positive change items and one open-ended question. Need items were scored as: no need (0), "met" need (1), or "unmet" need (2); "unmet" needs were further rated as weak, moderate, or strong. The total scores were derived by summing responses in that category. The "needs" items were in five domains: existential survivorship (14 items), comprehensive care (6 items), information (3 items), QoL (2 items), and relationships (3 items), as well as six positive change items. This scale has good acceptability, internal consistency, and validity [22].

2.3.3. Measures for Participation and Quality of Life. The cancer rehabilitation evaluation system-short form (CARESSF) [32], a self-administered 59-item questionnaire, the cancer specific rehabilitation needs, and QoL. Global scores indicate QoL with summary scores for 5 domains (physical, 
psychosocial, medical interaction, and marital and sexual function). The participant rated the degree to which a given problem applied during the 4 weeks before the survey. Scoring was based on a four-point Likert scale, with higher scores indicating more difficulty or impairment.

The depression anxiety stress scale-21 (DASS) [33], a set of three 7-item self-report scales, measured the negative emotional states of depression, anxiety, and stress. Participants rated the extent to which they experienced each state over the past week on a 4-point Likert rating scale. Subscale scores were derived by totalling and multiplying by two to ensure consistent interpretation with the longer DASS 42item version, as per the manual.

2.4. Statistical Analysis. All statistical analysis was conducted using SPSS for Windows software version 16 (SPSS, Chicago, IL). Kolmogorov-Smirnov tests were used to test for normality. For the CaSUN measure all 35 items were included in the calculation of the sum of total "met," total "unmet" and total needs. Factor analysis for each domain of the CaSUN was conducted. The responses format of the positive change items was interpreted descriptively. A complete case analysis strategy was used; hence, cases with missing values on a variable were excluded from the analyses of that particular variable.

\section{Results}

3.1. Sample Characteristics. Mean age of BC participants was 57 years (all female), with median time since definitive diagnosis of 2.2 years (IQR 1.4, 4.9), while mean age of the BT participants was 51 years (range 21-77 years), and the majority were female (56\%) with median time since diagnosis of 2.1 years. More than a third (39\%) of the BT patients had high grade gliomas (grade IV) and underwent surgery; two-thirds had radiotherapy (64.2\%) and less than half had chemotherapy (43\%). Over half of the BC patients had Bloom-Richardson-Elston (BRE) grade 3 tumours (54\%), were estrogen-receptor positive $(85 \%)$ and with lymph node involvement $(66 \%)$. More than a third $(37 \%)$ of BC patients had breast conservation surgery (lumpectomy) with axillary clearance (Table 1).

3.2. Current Symptoms. Both patient groups reported various condition-related symptoms. The main symptoms in BT patients were pain/headache (56\%), ataxia (44\%), seizures (43\%), paresis (37\%), cognitive dysfunction (36\%), and visual impairment (35\%). Three quarters of the BC patients reported some degree of breast related pain $(75 \%)$, with $39 \%(n=24)$ rating the pain as $>5$ on a 10 -point scale. Other symptoms in BC patients included upper limb weakness (32\%), pain limiting shoulder movement (31\%), and lymphedema (29\%) (Table 1).

3.3. Current Level of Psychological Wellbeing and QoL. Compared with a normative sample of the Australian population (13\%) [33], a substantial number of participants reported high levels of depression: BC (22\%); BT (20\%) (measured by DASS). Although the stress scores were almost similar (12\% each), higher level of anxiety was expressed only by BC participants (19\%) (Table 2).

The highest median scores (indicating greatest distress or disability) in the CARES-SF for BT participants were found on subscales for "physical" (median $(\mathrm{Md})=1.0, \mathrm{IQR}=0.5,1.5)$ (evaluating problems with daily activity) and "psychological" factors (evaluating communication and relationship) ( $\mathrm{Md}=$ $0.6, \mathrm{IQR}=0.4,1.1$ ), while for $\mathrm{BC}$ participants highest scores were in "marital" $(\mathrm{Md}=1.0, \mathrm{IQR}=0,2)$ and "physical" factors $(\mathrm{Md}=0.5, \mathrm{IQR}=0.3,1.3)($ Table 2$)$.

3.4. Supportive Care Needs. Except for one participant in each group, both BT $(99.1 \%, n=105)$ and BC groups $(98.8 \%$, $n=84$ ) reported at least one need ("met" or "unmet"). BC patients had slightly higher numbers of reported needs ("met" or "unmet"): mean 13.7 needs (range 0-31) compared to mean 11.6 needs (range $0-29$ ) in BT patients (Table 2).

3.4.1. "Unmet" Needs. The majority of participants in the BC group ( $85 \%, n=72$ ) endorsed at least one "unmet" need, with an average of $6.0 \pm 6.3$ "unmet" needs (range $0-28$ ). More than one-third of these participants (41.2\%) rated their "unmet" needs as severe. The ten most frequently endorsed "unmet" needs by BC patients are shown in Table 3.

Compared to BC participants slightly fewer BT participants endorsed at least one "unmet" need $(n=81,76 \%)$, with an average of $4.1 \pm 4.9$ (range $0-26$ ) "unmet" needs. Similar to the BC group, more than one-third of the participants $(41.2 \%)$ rated their "unmet" needs as severe. The ten most frequently endorsed "unmet" needs by BT patients are shown in Table 4.

Both patient groups had similar "unmet" needs with the highest needs related to dealing with fears of cancer spreading, making decision about life, stress, need for complementary medicine, and hospital parking. Additional "unmet" needs in the BC group included adjusting the body image, managing ongoing side effects, and concern about the coordinated care from treating clinicians. The BT group's additional "unmet" needs included communication with health care professionals, peers, finance, and family support.

3.4.2. "Met" Needs. Of the total BC participants, $96.5 \%(n=$ 82) reported at least one "met" need, with an average of $7.7 \pm 4.6$ (range 0-27) "met" needs. Similarly, most of the BT participants $98.1 \%(n=104)$ reported at least one "met" need, with an average of $7.3 \pm 4.0$ (range $0-24$ ) "met" needs. The ten most frequently endorsed "met" needs by BC patients are shown in Table 5 and by BT patients in Table 6 .

Most common "met" needs were similar in both patient groups, the highest number of "met" needs relating to medical care, information, local health services, communications with treating medical team and healthcare professionals, and emotional support. Additional "met" needs in the BC group included communication with peers and overall help and support. The BT group's additional "met" needs included managing side effects and financial support. 
TABLE 1: Sociodemographic characteristics of participants $(n=85)$.

\begin{tabular}{|c|c|c|}
\hline & \multicolumn{2}{|c|}{$n,(\%)$ (unless otherwise stated) } \\
\hline & $\begin{array}{l}\text { Breast cancer } \\
\quad(n=85)\end{array}$ & $\begin{array}{l}\text { Brain tumour } \\
\quad(n=106)\end{array}$ \\
\hline \multicolumn{3}{|l|}{ Demographic factors } \\
\hline \multicolumn{3}{|l|}{ Age (years) } \\
\hline (Mean (SD), range) & $57.6(10.6), 34.8-81.8$ & $\begin{array}{c}52.6(13.6) \\
22.1-78.5\end{array}$ \\
\hline \multicolumn{3}{|c|}{ Sex } \\
\hline Female & $85(100)$ & $61(57.5)$ \\
\hline \multicolumn{3}{|l|}{ Marital status } \\
\hline Married/partner & $53(62.4)$ & $81(76.4)$ \\
\hline \multicolumn{3}{|l|}{ Living with } \\
\hline Partner/family & $68(80.0)$ & $81(76.4)$ \\
\hline \multicolumn{3}{|l|}{ Education } \\
\hline Secondary & $37(43.5 \%)$ & $55(51.9)$ \\
\hline Tertiary & $43(50.6 \%)$ & $47(44.3)$ \\
\hline Smokers & $13(15.3 \%)$ & $17(16.0)$ \\
\hline Consumes alcohol & $46(54.1 \%)$ & $45(42.5)$ \\
\hline \multicolumn{3}{|l|}{ Clinical characteristics } \\
\hline \multicolumn{3}{|l|}{ Disease duration (years) } \\
\hline$(\mathrm{Md},(\mathrm{IQR}))$ & $2.2(1.4-4.9)$ & $2.1(0.8,4.0)$ \\
\hline Tumour grading & $\operatorname{BRE}^{*}(n=83)$ & $\begin{array}{l}\mathrm{WHO}^{* *} \\
(n=96)\end{array}$ \\
\hline Grade 1 & $10(12.0 \%)$ & $14(14.6)$ \\
\hline Grade 2 & $28(33.7 \%)$ & $30(31.3)$ \\
\hline Grade 3 & $45(54.2 \%)$ & $15(15.6)$ \\
\hline Grade 4 & N/A & $37(38.5)$ \\
\hline Surgery & $85(100 \%)$ & $105(99.1)$ \\
\hline$\geq 2$ surgery episodes & $36(42.4 \%)$ & $33(31.4)$ \\
\hline Chemotherapy & $63(74.1 \%)$ & $45(42.5)$ \\
\hline Multiple episode & $54(96.4 \%)$ & $19(42.2)$ \\
\hline Side effects & $60(70.6 \%)$ & $31(68.9)$ \\
\hline Radiotherapy & $63(74.1 \%)$ & $68(64.2)$ \\
\hline Multiple episode & $48(76.2 \%)$ & $44(64.7)$ \\
\hline Side effects & $47(55.3 \%)$ & $45(66.2)$ \\
\hline Currently on treatment & $55(64.7 \%)$ & \\
\hline \multicolumn{3}{|l|}{ Comorbidities } \\
\hline Hypertension & $27(31.8 \%)$ & $30(28.3)$ \\
\hline Diabetes & $5(5.9 \%)$ & $5(4.7)$ \\
\hline Depression & $28(32.9 \%)$ & $12(11.3)$ \\
\hline Pain & $63(74.1 \%)$ & $59(55.7)$ \\
\hline \multicolumn{3}{|c|}{ VAS pain score (0: no pain; 10: extreme pain) } \\
\hline Mean (SD), range & $3.8(2.1), 1-8$ & $3.0(2.0,5.0)$ \\
\hline
\end{tabular}

IQR: interquartile range, Md: median, $n$ : total number, SD: standard deviation, VAS: visual analogue scale.

* BRE: Bloom-Richardson-Elston grading.

** WHO: World Health Organisation classification of brain tumours (gliomas). 
TABLE 2: Descriptive statistics for subscales of the depression anxiety stress scale, cancer rehabilitation evaluation system-short form and cancer survivor unmet needs measure.

\begin{tabular}{|c|c|c|}
\hline \multirow{2}{*}{ Scales } & \multicolumn{2}{|c|}{ Statistics } \\
\hline & $\begin{array}{l}\text { Breast cancer } \\
\quad(n=85)\end{array}$ & $\begin{array}{l}\text { Brain tumour } \\
\quad(n=106)\end{array}$ \\
\hline \multicolumn{3}{|l|}{ DASS (Md, IQR) } \\
\hline Depression $(0-42)$ & $2(0,12)$ & $4(0,10)$ \\
\hline Anxiety $(0-42)$ & $4(2,8)$ & $2,(0,6)$ \\
\hline Stress $(0-42)$ & $8(4,14)$ & $6(2,14)$ \\
\hline \multicolumn{3}{|l|}{ DASS group: $(n, \%)$} \\
\hline \multicolumn{3}{|l|}{ Depression } \\
\hline Normal/mild (0-13) & $66(77.6 \%)$ & $85(80.2)$ \\
\hline Moderate/severe/extreme severe $(\geq 14)$ & $19(22.4 \%)$ & $21(19.8)$ \\
\hline \multicolumn{3}{|l|}{ Anxiety } \\
\hline Normal/mild (0-9) & $69(81.2 \%)$ & $93(87.7)$ \\
\hline Moderate/severe/extreme severe $(\geq 10)$ & $16(18.8 \%)$ & $13(12.3)$ \\
\hline \multicolumn{3}{|l|}{ Stress } \\
\hline Normal/mild (0-18) & $75(88.2 \%)$ & $93(87.7)$ \\
\hline Moderate/severe/extreme severe $(\geq 19)$ & $10(11.8 \%)$ & $13(12.3)$ \\
\hline \multicolumn{3}{|l|}{ CARES-SF (global scores) (Md, IQR) } \\
\hline Physical (0-4) & $0.5(0.3,1.3)$ & $1.0,(0.5,1.5)$ \\
\hline Psychological (0-4) & $0.4(0.3,1)$ & $0.6(0.4,1.1)$ \\
\hline Medical (0-4) & $0(0,0.5)$ & $0(0,1.0)$ \\
\hline Martial (0-4) & $1(0,2)$ & $0.2(0,0.8)$ \\
\hline Sexual $(0-4)$ & $0.3(0.1,0.6)$ & $0.3(0,1.5)$ \\
\hline Overall (0-4) & $0.5(0.4,1)$ & $0.6(0.4,1.0)$ \\
\hline \multicolumn{3}{|l|}{ CaSUN (mean (SD), range) } \\
\hline Total needs & $13.7(6.5), 0-31$ & $11.6(5.9), 0-29$ \\
\hline Total "unmet" needs & $6.0(6.3) 0-28$ & $4.1(4.9), 0-26$ \\
\hline Total "met" needs & 7.7 (4.6), 0-27 & $7.3(4.0), 0-24$ \\
\hline
\end{tabular}

TABLE 3: Breast cancer survivors' most frequently endorsed ten "unmet" needs $(n=85)$.

\begin{tabular}{|c|c|c|c|}
\hline Rank $^{*}$ & CaSUN need items & $n$ & $\%$ \\
\hline 1 & I need help to manage my concerns about the cancer coming back & 35 & 41.2 \\
\hline 2 & I need help to adjust to changes to the way I feel about my body & 29 & 34.1 \\
\hline 3 & I need help to reduce stress in my life & 29 & 34.1 \\
\hline 4 & $\begin{array}{l}\text { I need help to manage ongoing side effects and/or complications of } \\
\text { treatment }\end{array}$ & 29 & 34.1 \\
\hline 5 & I need access to complementary and/or alternative therapy services & 26 & 30.6 \\
\hline 6 & $\begin{array}{l}\text { I need to know that all my doctors talk to each other to coordinate } \\
\text { my care }\end{array}$ & 22 & 25.9 \\
\hline 7 & I need more accessible hospital parking & 21 & 24.7 \\
\hline 8 & $\begin{array}{l}\text { I need to feel like I am managing my health together with the medical } \\
\text { team }\end{array}$ & 18 & 21.2 \\
\hline 9 & I need any complaints regarding my care to be properly addressed & 18 & 21.2 \\
\hline 10 & $\begin{array}{l}\text { I need help to try to make decisions about my life in the context of } \\
\text { uncertainty }\end{array}$ & 18 & 21.2 \\
\hline
\end{tabular}

CaSUN: cancer survivors' unmet needs measure; $n$ : total number.

${ }^{*}$ All items also reported by BT participants are bolded. 
TABLE 4: Brain tumour survivors' most frequently endorsed ten "unmet" needs ( $n=106)$.

\begin{tabular}{|c|c|c|c|}
\hline Rank $^{*}$ & CaSUN need items & $n$ & $\%$ \\
\hline 1 & $\begin{array}{l}\text { I need help to try to make decisions about my life in the context of } \\
\text { uncertainty }\end{array}$ & 28 & 26.4 \\
\hline 2 & I need help to manage my concerns about the cancer coming back & 26 & 24.5 \\
\hline 3 & I need help to reduce stress in my life & 25 & 23.5 \\
\hline 4 & I need to talk to others who have experienced cancer & 25 & 23.5 \\
\hline 5 & I need more accessible hospital parking & 23 & 21.7 \\
\hline 6 & $\begin{array}{l}\text { I need an ongoing case manager to whom I can go to find out about } \\
\text { services whenever they are needed }\end{array}$ & 22 & 20.8 \\
\hline 7 & I need access to complementary and/or alternative therapy services & 18 & 17.0 \\
\hline 8 & I need help to know how to support my partner and/or family & 18 & 17.0 \\
\hline 9 & $\begin{array}{l}\text { I need help to find out about financial support and/or government } \\
\text { benefits to which I am entitled }\end{array}$ & 17 & 16.0 \\
\hline 10 & $\begin{array}{l}\text { I need help to adjust to changes in my quality of life as a result of my } \\
\text { career }\end{array}$ & 16 & 15.1 \\
\hline
\end{tabular}

CaSUN: cancer survivors' unmet needs measure; $n$ : total number.

*All items also reported by BC participants are bolded.

3.4.3. Domains of Needs. The domains of highest "met" needs for both BC and BT patients were very similar. The most frequently endorsed "met" needs by the $\mathrm{BC}$ group were in "comprehensive cancer care" (mean $2.6 \pm 1.3$ ), followed by "existential survivorship" (mean $2.5 \pm 2.6$ ). Likewise, the most frequently endorsed "unmet" needs in the BC group were in "existential survivorship domain" (mean $2.7 \pm 3.5$, range 0-13) followed by "comprehensive cancer care" domain (mean $1.1 \pm 1.4$, range $0-6$ ) (Table 7, Figure 1).

The most frequently endorsed total "met" needs by the BT patients were also in "comprehensive cancer care" (mean $2.8 \pm 1.3$ ), followed by "information" domain (mean $1.7 \pm 1.2$ ) and existential survivorship (mean $1.6 \pm 1.9$ ). Similar to the BC group, the most frequently endorsed "unmet" needs by BT group were in "existential survivorship" (mean $1.9 \pm 2.6$ ) followed by "comprehensive cancer care" (mean $0.8 \pm 1.1$ ) (Table 7, Figure 1).

\section{Discussion}

To our knowledge, this cross-sectional study is the first to report comparative ongoing "needs" in two diverse groups of cancer populations (BC and $\mathrm{BT}$ ) in the community following successful completion of their treatment. The BT and BC survivors in this study are similar to those in other studies in terms of age, gender, disease severity, and treatment $[10$, 34-38]. The median time since diagnosis was just over 2 years with established impairments and functional disability. Although most cancer survivors in this study seem to have adjusted well, a significant proportion experienced transient and/or persistent physical and psychosocial morbidities which necessitated some form of care. Almost all participants from both BC and BT groups reported at least one need ("met" or "unmet") and over two-thirds reported that one or more of their needs were unmet. BC patients reported a slightly higher number of "unmet" needs compared to BT patients ( $85 \%$ versus $76 \%$ ). Of these "unmet" needs, over $40 \%$ in both groups reported that their "unmet" needs were severe.
As expected, there were commonalities and overlap amongst the supportive care needs endorsed by BT and BC survivors. Highest levels of "met" needs across the survivorship continuum reported by both groups were in the "comprehensive care," "existential survivorship," and "information" domains, consistent with those in other oncological cohorts such as gynaecology, prostrate, and colorectal cancers $[24,26]$. Remarkably, the highest levels of the "unmet" needs in both groups were similar, in the domains of "existential survivorship" and "comprehensive care." Further, a substantial number of participants in both groups reported high levels of depression, anxiety, and stress (measured by DASS), compared with only $13 \%$ in an Australian normative sample [33].

Advanced medical management in cancer has significantly improved survival rate both in $\mathrm{BC}$ and $\mathrm{BT}$ populations, and there is growing recognition of these conditions as a long-term illnesses impacting psychological functioning and QoL $[39,40]$. However, the physical and psychological morbidity and needs associated with these impairments, as in other cancer patients, can be underestimated [15, 41]. Understanding the long-term posttreatment impact of cancer and the needs of these patients is important as followup moves from acute settings to community health services.

This study provides an overview of the commonalities and discrepancies of the needs from the perspective of $\mathrm{BC}$ and BT patients across the survivorship trajectory. The findings of this study not only validate the ongoing challenges of survivorship reported by studies in other oncological groups [24-26, 42-44], but also are an important step towards understanding the problems with which a growing number of cancer survivors require assistance in the community. This information will assist in evidence-based planning and management and can improve clinical service delivery in identified areas for improved patient outcomes [26, 45].

This study has some potential limitations. First, this is a cross-sectional study, which limits the ability to draw causal relationships between the many domains of reported needs 
TABLE 5: Breast cancer survivors' most frequently endorsed "met" needs $(n=85)$.

\begin{tabular}{llcc}
\hline Rank $^{*}$ & CaSUN need items & $n$ & \% \\
\hline $\mathbf{1}$ & I need the very best medical care & 71 & 53.5 \\
$\mathbf{2}$ & I need up-to-date information & 58.8 \\
$\mathbf{3}$ & I need to feel like I am managing my health together with the medical team & 50 & 50 \\
$\mathbf{4}$ & I need information provided in a way that I can understand & 46 & 54.1 \\
$\mathbf{5}$ & I need local health care services that are available when I require them & 52.9 \\
$\mathbf{6}$ & I need to know that all my doctors talk to each other to coordinate my care & 50.6 \\
$\mathbf{7}$ & I need emotional support to be provided for me & 43 & 42 \\
8 & I need to talk to others who have experienced cancer & 32 & 37.4 \\
$\mathbf{9}$ & My family and/or partner needs information relevant to them & 31.8 \\
10 & I need help to move on with my life & 27 & 24 \\
\hline
\end{tabular}

CaSUN: cancer survivors' unmet needs measure; $n$ : total number.

* All items also reported by BT participants are bolded.

TABLE 6: Brain tumour survivors' most frequently endorsed "met" needs $(n=106)$.

\begin{tabular}{|c|c|c|c|}
\hline Rank $^{*}$ & CaSUN need items & $n$ & $\%$ \\
\hline 1 & I need the very best medical care & 89 & 84.0 \\
\hline 2 & I need local health care services that are available when I require them & 70 & 66.0 \\
\hline 3 & I need to feel like I am managing my health together with the medical team & 67 & 63.2 \\
\hline 4 & I need up-to-date information & 62 & 58.5 \\
\hline 5 & I need information provided in a way that I can understand & 61 & 57.5 \\
\hline 6 & My family and/or partner needs information relevant to them & 57 & 53.8 \\
\hline 7 & I need to know that all my doctors talk to each other to coordinate my care & 57 & 53.8 \\
\hline 8 & I need help to manage ongoing side effects and/or complications of treatment & 38 & 35.8 \\
\hline 9 & I need emotional support to be provided for me & 36 & 34.0 \\
\hline 10 & I need help to find out about financial support and/or government benefits to which I am entitled & 33 & 31.1 \\
\hline
\end{tabular}

CaSUN: cancer survivors' unmet needs measure; $n$ : total number.

${ }^{*}$ All items also reported by BC participants are bolded.

TABLE 7: Participants' endorsement of the cancer survivor unmet needs measure ranked by total "met" needs.

\begin{tabular}{|c|c|c|c|c|c|c|c|c|c|}
\hline \multirow{3}{*}{ Rank } & \multirow{3}{*}{ CaSUN factor } & \multicolumn{4}{|c|}{ Brain tumour $(n=106)$} & \multicolumn{4}{|c|}{ Breast cancer $(n=85)$} \\
\hline & & \multicolumn{2}{|c|}{ Total met need } & \multicolumn{2}{|c|}{ Total unmet need } & \multicolumn{2}{|c|}{ Total met need } & \multicolumn{2}{|c|}{ Total unmet need } \\
\hline & & Mean (SD) & Range & Mean (SD) & Range & Mean (SD) & Range & Mean (SD) & Range \\
\hline 1 & Comprehensive cancer care & $2.8(1.4)$ & $0-5$ & $0.8(1.1)$ & $0-5$ & $2.6(1.3)$ & $0-5$ & $1.1(1.4)$ & $0-6$ \\
\hline 2 & Existential survivorship & $1.6(1.9)$ & $0-11$ & $1.9(2.6)$ & $0-12$ & $2.5(2.6)$ & $0-13$ & $2.7(3.5)$ & $0-13$ \\
\hline 3 & Information & $1.7(1.2)$ & $0-3$ & $0.3(0.7)$ & $0-3$ & $1.5(1.1)$ & $0-3$ & $0.4(0.7)$ & $0-3$ \\
\hline 4 & Quality of life & $0.5(0.6)$ & $0-2$ & $0.3(0.6)$ & $0-2$ & $0.3(0.6)$ & $0-2$ & $0.5(0.7)$ & $0-2$ \\
\hline 5 & Relationship & $0.1(0.4)$ & $0-2$ & $0.4(0.8)$ & $0-3$ & $0.2(0.6)$ & $0-3$ & $0.5(0.9)$ & $0-3$ \\
\hline
\end{tabular}

CaSUN: cancer survivor unmet needs measure; $n$ : total number; SD: standard deviation.

and functional improvements. Second, as this study utilized relatively small selective cohorts listed on a database held at single tertiary institution, with strict inclusion criteria who volunteered to participate, which may limit generalizability of findings. The study cohorts, however, are similar to cohorts reported in other studies and represent a wide sample of BT and BC survivors in the community. Participants in this study were complex in terms of disease severity, symptoms, and comorbidities (reflective of those seen in clinical practice). In an attempt to reduce recall and information bias, the assessors worked individually with each participant and all questions were limited to the person's current situation. Thirdly, we acknowledge that we were not able to capture and evaluate various other needs and problems (such as spiritual and religious needs) beyond those included within the domains of the CaSUN, this was beyond the scope of this study. The CaSUN measure, however, was broad and expansive.

\section{Conclusions}

BT and BC are complex and challenging conditions, with multifaceted physical, psychological, and cognitive disabilities and participatory limitations that require an integrated interdisciplinary approach [39, 40]. Understanding the impact of $\mathrm{BT}$ and $\mathrm{BC}$ in the longer term (beyond the acute phase) is important, as current medical advances have 


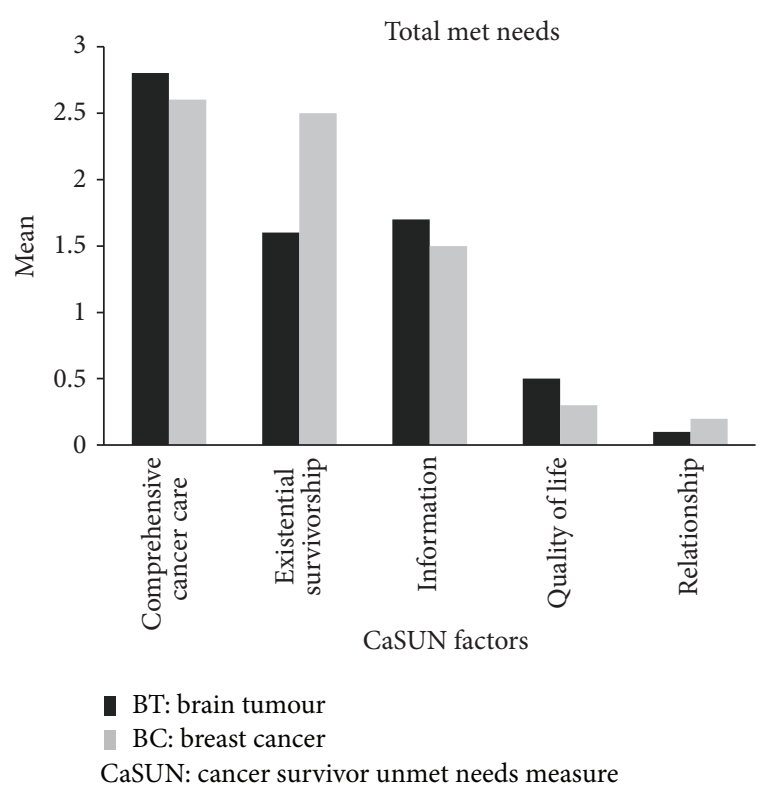

(a)

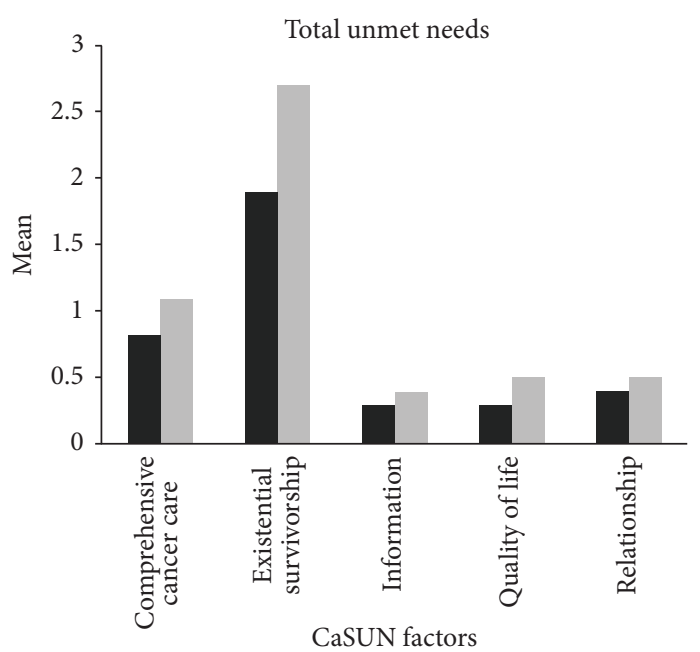

BT: brain tumour
BC: breast cancer
CaSUN: cancer survivor unmet needs measure

(b)

FIGURE 1: Participants' endorsement of the cancer survivor unmet needs measure factors. BT = brain tumour; $\mathrm{BC}=$ breast cancer; CaSUN $=$ cancer survivor unmet needs measure.

improved patient survival and shifted care patient management to the ambulatory care sector. Supportive care needs were frequently reported by both BT and BC survivors in the longer term along the disease-survivorship continuum, with over two-thirds reporting one or more of their needs not unmet. The most frequently reported needs were in domains of "existential survivorship" and "comprehensive care." The specific needs experienced by these survivors were similar many years after apparently successful cancer treatment. Findings from this study highlight the multifaceted needs and problems reported by these complex patient populations, which needs to be assessed and addressed by all healthcare professionals involved in the follow-up care. These findings, however, need to be confirmed in robust clinical trials with larger study samples in multiple settings.

\section{Abbreviations}

BC: Breast cancer

BT: $\quad$ Brain tumour

BRE: $\quad$ Bloom-Richardson-Elston grading

CaSUN: Cancer survivor unmet needs

CARES-SF: Cancer rehabilitation evaluation system-short form

DASS: Depression anxiety stress scale

IQR: Interquartile range

VAS: Visual analogue scale

WHO: World Health Organisation.

\section{Ethical Approval}

The study was approved by the Royal Melbourne Hospital Ethical Committee and informed consent was obtained from all the subjects.

\section{Disclosure}

The corresponding author has the right to grant on behalf of all authors and does grant on behalf of all authors an exclusive license to the ISRN Rehabilitation.

\section{Conflict of Interests}

The authors declare that there is no conflict of interests regarding the publication of the paper.

\section{Acknowledgments}

The authors are grateful to all participants with breast cancer in this study. The authors particularly wish to thank Ms. L. Oscari and Drs. N. Zhang and I. Rajapaksa for patient assessments and T. Khan for data entry. The authors also acknowledge Professor B. Mann and Associate Professor Kate Drummond of Cancer Services at the Royal Melbourne Hospital.

\section{References}

[1] Australian Institute of Health and Welfare (AIHW) and Australasian Association of Cancer Registries (AACR), Cancer in Australia: An Overview, 2012, Cancer Series no. 74. Cat. No. CAN 70, AIHW, Canberra, Australia, 2012.

[2] World Health Organisation, The Global Burden of Disease: 2004 Update, WHO, Geneva, Switzerland, 2008.

[3] A. Arber, S. Faithfull, M. Plaskota et al., "A study of patients with a primary malignant brain tumour and their carers: symptoms and access to services," International Journal of Palliative Nursing, vol. 16, no. 1, pp. 24-30, 2010. 
[4] D. M. Parkin, S. L. Whelan, and J. Ferlay, Cancer Incidence in Five Continents, vol. 1-8, no. 7 of IARC Cancerbase, Lyon, France, 2005.

[5] Australian Institute of Health and Welfare (AIHW), Breast Cancer in Australia: An Overview. National Breast and Ovarian Cancer Centre, Cancer Series no 50. Cat no CAN 46, AIHW, Canberra, Australia, 2009.

[6] A. Flowers, "Brain tumors in the older person," Cancer Control, vol. 7, no. 6, pp. 523-538, 2000.

[7] A. Jemal, R. Siegel, E. Ward, Y. Hao, J. Xu, and M. J. Thun, "Cancer statistics, 2009," CA Cancer Journal for Clinicians, vol. 59, no. 4, pp. 225-249, 2009.

[8] Brain Foundation, "Brain tumour and braincancer," 2011, http://brainfoundation.org.au/medical-info/brain-tumour.

[9] C.-H. Yip, R. A. Smith, B. O. Anderson et al., "Guideline implementation for breast healthcare in low- and middleincome countries: early detection resource allocation," Cancer, vol. 113, no. 8, pp. 2244-2256, 2008.

[10] M. E. Huang, J. E. Wartella, and J. S. Kreutzer, "Functional outcomes and quality of life in patients with brain tumors: a preliminary report," Archives of Physical Medicine and Rehabilitation, vol. 82, no. 11, pp. 1540-1546, 2001.

[11] G. Poggi, M. Liscio, V. Pastore et al., "Psychological intervention in young brain tumor survivors: the efficacy of the cognitive behavioural approach," Disability and Rehabilitation, vol. 31, no. 13, pp. 1066-1073, 2009.

[12] B. Thewes, P. Butow, A. Girgis, and S. Pendlebury, "The psychosocial needs of breast cancer survivors; a qualitative study of the shared and unique needs of younger versus older survivors," Psycho-Oncology, vol. 13, no. 3, pp. 177-189, 2004.

[13] K. L. Campbell, A. L. Pusic, D. S. Zucker et al., "A prospective model of care for breast cancer rehabilitation: function," Cancer, vol. 118, no. 8, pp. 2300-2311, 2012.

[14] V. Tang, M. Rathbone, J. Park Dorsay, S. Jiang, and D. Harvey, "Rehabilitation in primary and metastatic brain tumours: impact of functional outcomes on survival," Journal of Neurology, vol. 255, no. 6, pp. 820-827, 2008.

[15] D. J. Franklin, "Cancer rehabilitation: challenges, approaches, and new directions," Physical Medicine and Rehabilitation Clinics of North America, vol. 18, no. 4, pp. 899-924, 2007.

[16] N. M. Aziz and J. H. Rowland, "Trends and advances in cancer survivorship research: challenge and opportunity," Seminars in Radiation Oncology, vol. 13, no. 3, pp. 248-266, 2003.

[17] J. S. Carpenter, M. A. Andrykowski, P. Sloan et al., "Post mastectomy/post lumpectomy pain in breast cancer survivors," Journal of Clinical Epidemiology, vol. 51, pp. 1285-1292, 1998.

[18] T. Ownsworth, A. Hawkes, S. Steginga, D. Walker, and D. Shum, "A biopsychosocial perspective on adjustment and quality of life following brain tumor: a systematic evaluation of the literature," Disability and Rehabilitation, vol. 31, no. 13, pp. 1038-1055, 2009.

[19] F. A. Tager, P. S. McKinley, F. R. Schnabel et al., "The cognitive effects of chemotherapy in post-menopausal breast cancer patients: a controlled longitudinal study," Breast Cancer Research and Treatment, vol. 123, no. 1, pp. 25-34, 2010.

[20] F. Fehlauer, S. Tribius, A. Mehnert, and D. Rades, "Healthrelated quality of life in long term breast cancer survivors treated with breast conserving therapy: impact of age at therapy," Breast Cancer Research and Treatment, vol. 92, no. 3, pp. 217-222, 2005.

[21] K. K. Ness, E. B. Morris, V. G. Nolan et al., "Physical performance limitations among adult survivors of childhood brain tumors," Cancer, vol. 116, no. 12, pp. 3034-3044, 2010.
[22] K. Hodgkinson, P. Butow, G. E. Hunt et al., "The development and evaluation of a measure to assess cancer survivors' unmet supportive care needs: TheCaSUN (Cancer Survivors' Unmet Needs measure)," Psycho-Oncology, vol. 16, no. 9, pp. 796-804, 2007.

[23] H. S. Campbell, R. Sanson-Fisher, D. Turner, L. Hayward, X. S. Wang, and J. Taylor-Brown, "Psychometric properties of cancer survivors' unmet needs survey," Supportive Care in Cancer, vol. 19, no. 2, pp. 221-230, 2010.

[24] S. E. Harrison, E. K. Watson, A. M. Ward et al., "Primary health and supportive care needs of long-term cancer survivors: a questionnaire survey," Journal of Clinical Oncology, vol. 29, no. 15, pp. 2091-2098, 2011.

[25] K. Hodgkinson, P. Butow, G. E. Hunt, S. Pendlebury, K. M. Hobbs, and G. Wain, "Breast cancer survivors' supportive care needs 2-10 years after diagnosis," Supportive Care in Cancer, vol. 15 , no. 5, pp. 515-523, 2007.

[26] K. Hodgkinson, P. Butow, A. Fuchs et al., "Long-term survival from gynecologic cancer: psychosocial outcomes, supportive care needs and positive outcomes," Gynecologic Oncology, vol. 104, no. 2, pp. 381-389, 2007.

[27] F. Khan and B. Amatya, "Factors associated with long-term functional outcomes, psychological sequelae and quality of life in persons after primary brain tumour," Journal of NeuroOncology, vol. 111, no. 3, pp. 355-366, 2013.

[28] F. Khan, B. Amatya, J. F. Pallant, and I. Rajapaksa, "Factors associated with long-term functional outcomes and psychological sequelae in women after breast cancer," Breast, vol. 21, no. 3, pp. 314-320, 2012.

[29] F. Khan, B. Amatya, J. F. Pallant et al., "Multidisciplinary rehabilitation in women following breast cancer treatment: a randomized controlled trial," Journal of Rehabilitation Medicine, vol. 44, no. 9, pp. 788-794, 2012.

[30] American Joint Committee on Cancer (AJCC), Breast, in AJCC Cancer Staging Manual, Springer, New York, NY, USA, 2002.

[31] P. Kleihues, P. C. Burger, and B. W. Scheithauer, "The new WHO classification of brain tumours," Brain Pathology, vol. 3, no. 3, pp. 255-268, 1993.

[32] P. A. Ganz, C. A. C. Schag, J. J. Lee, and M.-S. Sim, "The CARES: a generic measure of health-related quality of life for patients with cancer," Quality of Life Research, vol. 1, no. 1, pp. 19-29, 1992.

[33] S. H. Lovibond and P. F. Lovibond, Manual for the Depression, Anxiety, Stress Scales, The Psychology Foundation of Australia Inc, Sydney, Australia, 1995.

[34] C. Clayforth, L. Fritschi, S. P. McEvoy et al., "Five-year survival from breast cancer in Western Australia over a decade," Breast, vol. 16, no. 4, pp. 375-381, 2007.

[35] N. Devoogdt, M. Van Kampen, I. Geraerts et al., "Physical activity levels after treatment for breast cancer: one-year followup," Breast Cancer Research and Treatment, vol. 123, no. 2, pp. 417-425, 2010.

[36] J.-G. Han, Y.-D. Jiang, C.-H. Zhang et al., "Clinicopathologic characteristics and prognosis of young patients with breast cancer," Breast, vol. 20, no. 4, pp. 370-372, 2011.

[37] M. E. Huang, D. X. Cifu, and L. Keyser-Marcus, "Functional outcomes in patients with brain tumor after inpatient rehabilitation: comparison with traumatic brain injury," American Journal of Physical Medicine and Rehabilitation, vol. 79, no. 4, pp. 327-335, 2000.

[38] M. Bartolo, C. Zucchella, A. Pace et al., "Early rehabilitation after surgery improves functional outcome in inpatients with 
brain tumours," Journal of Neuro-Oncology, vol. 107, no. 3, pp. 537-544, 2012.

[39] F. Khan, B. Amatya, L. Ng et al., "Multidisciplinary rehabilitation for follow-up of women treated for breast cancer," Cochrane Database of Systematic Reviews, no. 12, Article ID CD009553, 2012.

[40] F. Khan, B. Amatya, L. Ng et al., "Multidisciplinary rehabilitation after primary brain tumour treatment," Cochrane Database of Systematic Reviews, no. 1, Article ID CD009509, 2013.

[41] N. A. Hutchison, "Cancer rehabilitation," Minnesota Medicine, vol. 93, no. 10, pp. 50-52, 2010.

[42] J. Armes, M. Crowe, L. Colbourne et al., "Patients' supportive care needs beyond the end of cancer treatment: a prospective, longitudinal survey," Journal of Clinical Oncology, vol. 27, no. 36, pp. 6172-6179, 2009.

[43] V. Beesley, E. Eakin, S. Steginga, J. Aitken, J. Dunn, and D. Battistutta, "Unmet needs of gynaecological cancer survivors: implications for developing community support services," PsychoOncology, vol. 17, no. 4, pp. 392-400, 2008.

[44] S. L. Sanders, E. O. Bantum, J. E. Owen, A. A. Thornton, and A. L. Stanton, "Supportive care needs in patients with lung cancer," Psycho-Oncology, vol. 19, no. 5, pp. 480-489, 2010.

[45] S. H. Campbell, M. Carey, R. Sanson-Fisher et al., "Measuring the unmet supportive care needs of cancer support persons: the development of the Support Person's Unmet Needs Surveyshort form," European Journal of Cancer Care, 2013. 


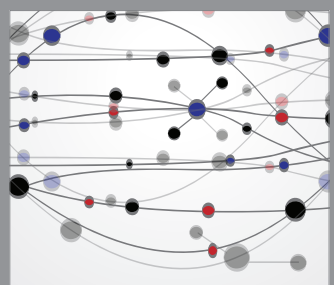

The Scientific World Journal
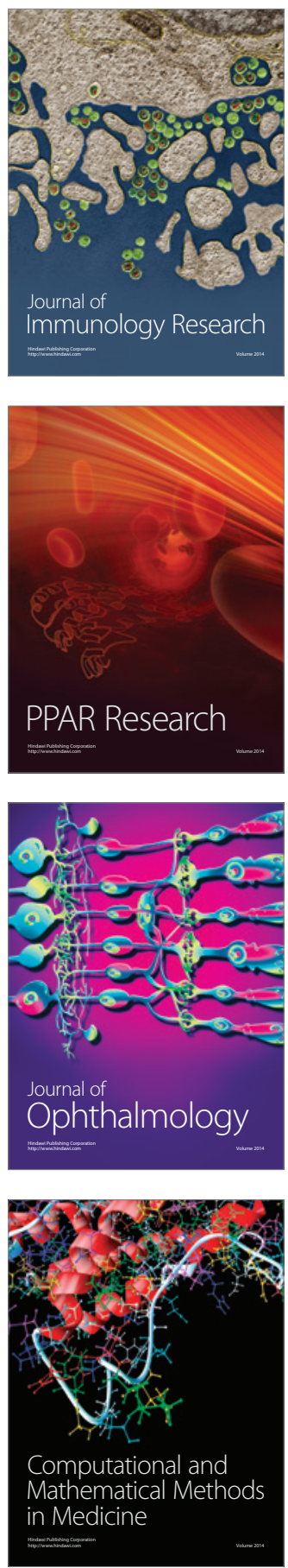

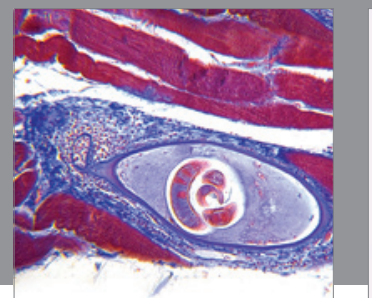

Gastroenterology

Research and Practice
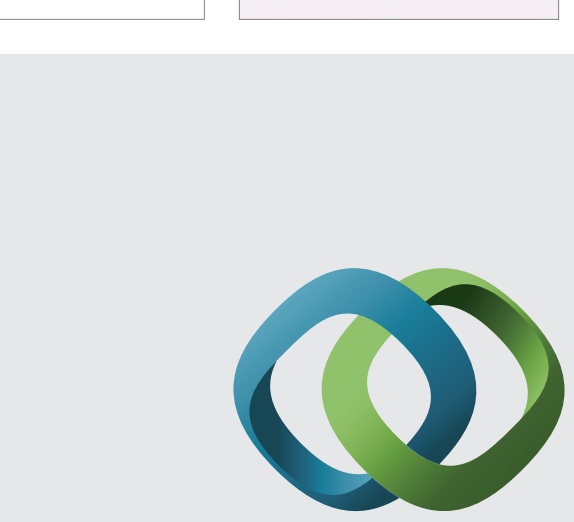

\section{Hindawi}

Submit your manuscripts at

http://www.hindawi.com
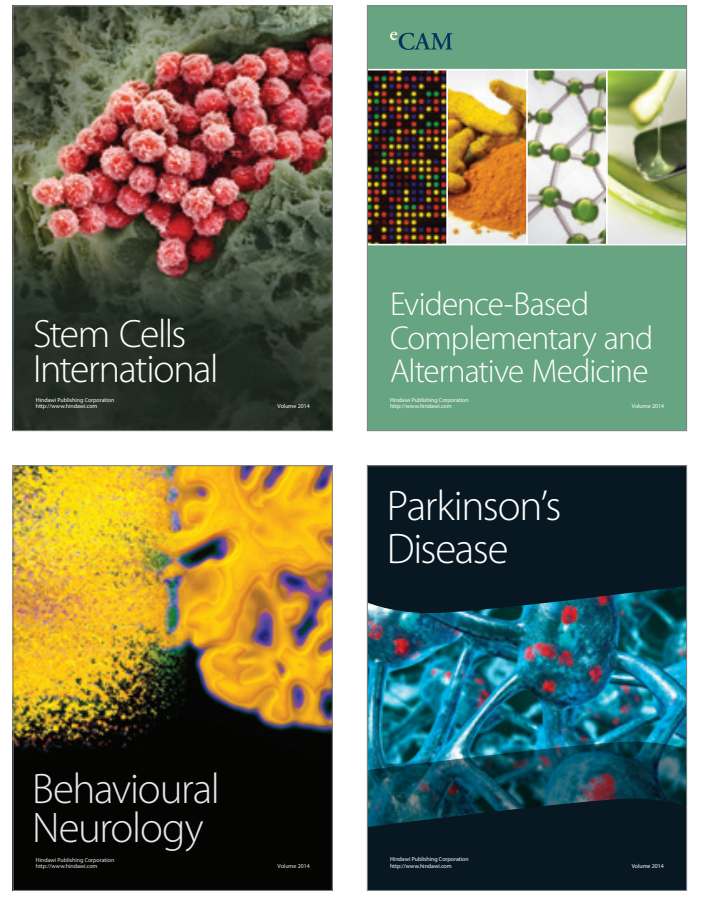
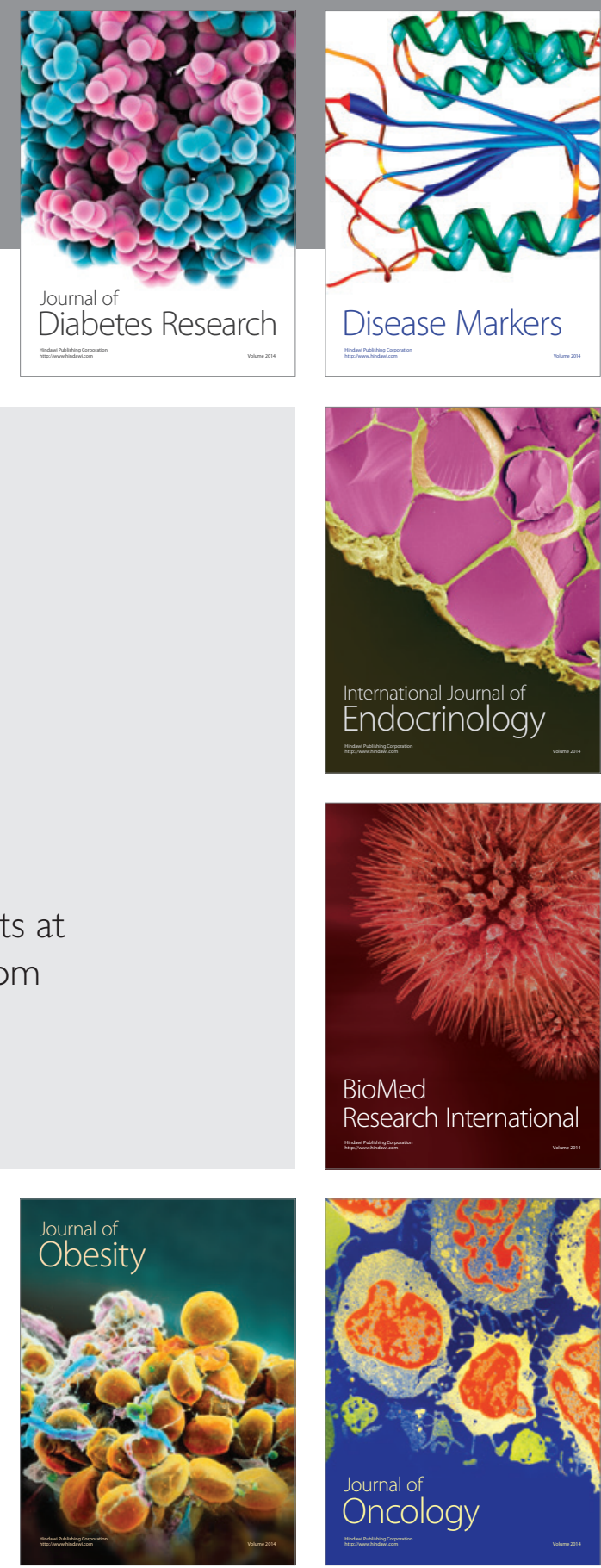

Disease Markers
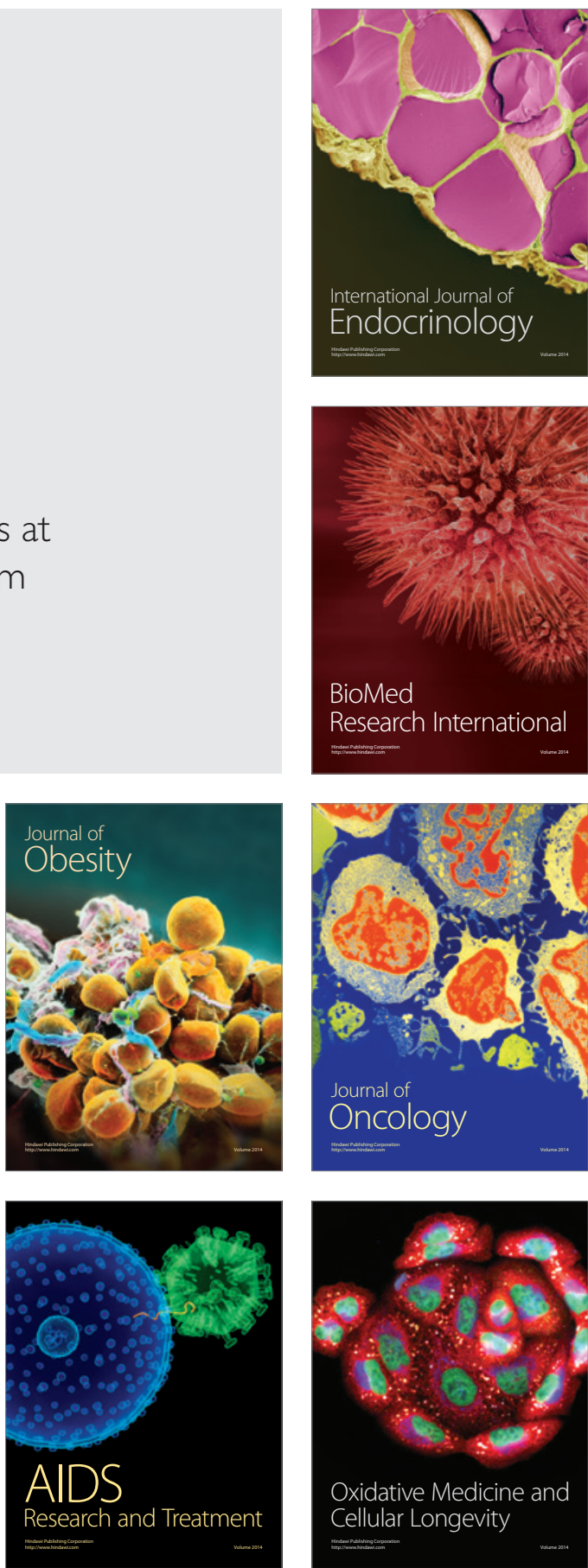